DOI: 10.24193/OJMNE.2020.32.04

\title{
THE MULTICULTURALISM POLICY IN EUROPE
}

Elena V. KUCHERYAVAYA, PhD

Faculty of Political Science and International Studies, University of Warsaw, Poland elenamulti@yahoo.com

Marta WITKOWSKA, PhD Faculty of Political Science and International Studies, University of Warsaw, Poland m.witkowska@uw.edu.pl

Viktoriya KALINOVSKAYA, M.A. Stolypin International Institute of Informatisation and Public Administration, RUDN University, Russia vi.arhipova@yandex.ru

Pavel SELEZNEV, PhD Financial University under the Government of the Russian Federation, Russia sps@ffa.ru

Svetlana ZUBANOVA, PhD Moscow Aviation Intitute (National Research University), Russia svet285@mail.ru

Aleksey FEDYAKIN, PhD Russian University of Transport, Russia avf2010@yandex.ru

\begin{abstract}
The aim of the article is the analysis of the genesis and contemporary content of the multiculturalism policy, implemented in European countries. The authors also consider the attitude of the European states to the increasing migrants flow. The attention is focused on the theoretical and practical differences in the understanding of the concept of "multiculturalism". Additionally, the analysis of the successful experience in implementing the multiculturalism policy from several non-European continents is presented in this article, which can be also applied in Europe. The authors also analyse the strategic mistakes and the reasons why the policy of multiculturalism is considered to be not effective in Europe today. The article is based on the case study, explicitdiagnostic, descriptive and evaluationary approaches, as well as an analysis of the works of various authors, who have been studying ethno-cultural diversity and multicultural societies for a long time, and on the critical discourse analysis of the recent publications in the media, related to the multiculturalism policy in Europe.
\end{abstract}

Keywords: multiculturalism, migration, multiculturalism policy in Europe, European lifestyle.

\section{Introduction. The aim and methodology}

Taking into consideration the new priorities of the European Commission for the new term (especially the importance of the fourth priority "Promoting our European lifestyle") ${ }^{20}$, the issue

\footnotetext{
${ }^{20}$ See more: European Commission, 6 Commission priorities for 2019-24, https://ec.europa.eu/info/strategy/priorities-2019-2024 (18.02.2020)
} 
of developing a common European concept of the multiculturalism policy (or alternatively developing a program supporting the actions of individual Member States in the face of the growing problem of migration) has become a common problem in public ${ }^{21}$ and scientific discussion (e.g. Triandafyllidou, Modood \& Meer 2012; Cuyjet et al. 2016; Meer 2016; McCoy 2018). For this reason, it is important to critically analyse the experience of the selected multicultural strategies on the level of the Member States. Culture is the realm used to uphold the concept of Europe; its ties, links, shared paths, as well as art, literature and music are the result of the diversity of the European Union, and the EU is a great example of a true commitment to interculturalism (Meer 2016).

The aim of the article is the analysis of the genesis and contemporary content of the multiculturalism policy, implemented in European countries. The attention is focused on the theoretical and practical differences in the understanding of the concept of "multiculturalism". Additionally, the description of the successful experience in implementing the policy of multiculturalism from other continents is presented in this article, which can be applied in the European countries. The authors analyse the strategic mistakes and the reasons, why the multiculturalism policy is considered to be not effective in Europe today.

The article uses theoretic research methods, mostly descriptive and evaluationary approaches, as well as the explicit-diagnostic one, which are based on the deductive reasoning and a generalisation of the gathered information.

The main sources of the analysis are the academic subject literature, political decisions on multiculturalism policies, research reports on multiculturalism policy in the particular countries, publications in the media, etc. The case study method, which has been used to analyse the multiculturalism policy in European countries, is particularly important for this research.

\section{The term "multiculturalism" in the different contexts}

The contemporary world is characterised by the existence of a large number of different cultures, which often interconnect within one state. The term "multiculturalism" appeared in

\footnotetext{
${ }^{21}$ See more, for example: European Commision, European Agenda on Migration - Legislative documents, https:/ec.europa.eu/home-affairs/what-we-do/policies/european-agenda-migration/proposal-implementationpackage en; European Commission, European Web Site on Integration. Migrant Integration Information and good practices, https://ec.europa.eu/migrant-integration/ (18.02.2020)
} 
Switzerland in 1957 to characterise the structure within the country, since Switzerland is a state where four languages are spoken and several different religions are manifested. However, at the beginning of the 1970s, the term "multiculturalism" received a slightly different content and became the marker of the multicultural state, which accepted the migrants, having already many of them, and at the same time this state respected the other cultures. As B. Parekh states, in the early 1970s the multicultural movement appeared in Canada and Australia for the first time, and then in the USA, Great Britain, Germany and the other countries (Parekh 1999). Immigration to Canada and Australia called into question the bi-culture and British-European monoculturalism. To the United States immigrants arrived mainly not from Europe, but from Latin America, the Caribbean and Asia. In the 1960s, Europe was already a continent covered by networks of immigrant flows, and by the end of the 1980s and the beginning of the 1990s, even those European countries that were the main suppliers of immigrants - Italy, Greece, Portugal, Spain, and Ireland, themselves began to include large immigrant communities, mostly non-Europeans. In the United States, the development of multiculturalism or "identity politics" was initiated by student and youth movements in the second half of the 1960s, which challenged established stereotypes and institutions. In the United States, these movements from the very beginning had a strong anti-racist connotation, which was associated with black people speaking for their rights. Similar movements, expressing pride in their culture of previously discriminated, marginalised and often despised ethnic groups, have spread among the indigenous population of countries created by immigrants, in particular in Canada, Australia and New Zealand (Terborn 2001).

Representatives of the Chicago School of Sociology introduced the study of the processes of cultural adaptation of migrants even before the development of such a term as "multiculturalism." The Chicago School of Sociology from 1915 to 1935 occupied a dominant position in American sociology and had a significant impact on the development of sociology as a whole, determining its empirical orientation. The problem of population migration was studied indepth by representatives of this school. This circumstance was caused by the fact that in the first quarter of the XX century the United States attracted a huge number of immigrants. In this regard, the issue of adaptation and, accordingly, the integration of migrants into a new society was extremely important. As a very valuable contribution to the issue of migration research must be considered the work "The Polish Peasant in Europe and America" by W. Thomas and F. Znaniecki (Sitnikova 2009). The subject of the above mentioned study was the family of Polish peasants 
who, after moving to the United States, entered the transition (adaptation) period from the old forms of social organisation to its modern forms. The theorists of Chicago School while studying migration processes made one of the first attempts to sociologically reassess the phenomenon of spatial displacements from the point of view of social changes taking place in society, as well as the consequences of migration for both the host society and the individuals. The adaptation features of migration were studied, which then formed the basis for developments on the cultural assimilation of migrants. On the basis of the Chicago School theoretical and practical findings (because the adaptation features of migrants were studied and described) we can argue that the beginning of critical multiculturalism has roots in the United States.

The term "multiculturalism" has a range of meanings in sociology and in political philosophy. In sociology it is a synonym for "ethnic pluralism" or "cultural pluralism", where various ethnic groups collaborate and enter into a dialogue without having to sacrifice their particular identities. For example, it can mean a mixed ethnic community area or a country, where many cultural traditions co-exist. Moreover, in sociology "multiculturalism" is the end-state of the natural or artificial process (e.g. legally-controlled immigration) and it occurs on a large national scale or on a smaller scale (e.g. the nation's communities). On a large scale, it can be a result of the legal or illegal migration around the world.

In political philosophy, the ideas of multiculturalism are focused on the ways in which societies should respond to cultural and religious differences. It is often associated with "identity policy", "the policy of difference", and "the policy of recognition". It is also a matter of economic interests and political power. Recently, political multiculturalist ideologies have been expanding in their use to include and define disadvantaged groups with arguments often focusing on ethnic and religious minorities, national minorities, and even people with disabilities. The article investigates the term "multiculturalism" in the most commonly understood, e.g. broad context, what includes the before mentioned issues.

During last years, multiculturalism has been the subject of wide debate.

Many debates over multiculturalism are centred on the question: whether or not multiculturalism is the appropriate way to deal with cultural diversity and immigrant integration. The arguments regarding the perceived rights to a multicultural education include the proposition, that it acts to demand recognition of the aspects concerning a group's culture subordination and its entire experience in contrast to the non-multicultural societies. Multiculturalism is seen by its 
supporters as a fairer system that allows people to truly express who they are within a society, that is more tolerant and that adapts better to social issues. In this case, the culture is not based on one race or religion, but it is rather the result of multiple factors, that change as the world changes.

\section{The multiculturalism policy: an analysis of selected cases}

Nowadays, the multiculturalism policy is one of the priorities in many countries, especially in Europe. In general, it should be said that European states first encountered multiculturalism in the period of colonisation of the $15^{\text {th }}-17^{\text {th }}$ centuries. Many modern cultural studies have noted that colonisation is the root cause of globalisation and cultural integration (Babich \& Rodionova 2009). In the countries such as Austria, France, Belgium, Denmark, Luxembourg, Sweden, Norway, Finland, Switzerland and, of course, Germany, the majority of immigrants were seen as "labour" migrants and refugees.

Many European countries faced the "challenges" of migration throughout the twentieth century. French experience can be considered as an illustration. In the first half of the XX century migrants began to come to France: "Russian aristocrats fled from the Bolshevik regime, Jews from the Nazi regime in Germany, and Armenians from Turkish genocide" (Veretevskaya 2018). Initially, French society treated migrants positively, but as the economic situation worsened, the attitude became more hostile. In 1889, the Citizenship Law was revised, which now gave the government the right to refuse immigrants to naturalise if they "did not deserve it" or were recognised as "undesirable". However, after the loss of a large number of able-bodied people during World War I, attitudes towards immigrants changed again and the legislation became more liberal. In the middle of the 20th century, a new flood of immigrants poured into France - after the war, Spaniards and Portuguese fled to France from autocracy and economic problems. In the 1960s immigrants from former French colonies began to come to work in large numbers. Algeria is an example. The Algerian colony has long been considered virtually and legally part of France. Algerian citizens, respectively, of both European and non-European descent, enjoyed the right of free movement to France, as well as French citizens - to Algeria. During the War of Independence, many French citizens living in Algeria rushed to their historic homeland. Algeria's independence did not stop the flow of immigration to France. Moreover, almost immediately after the recognition of the independence of Algeria, France and Algeria signed the Evian Agreements, which, in particular, laid the legal basis for labor immigration. In the future France will attempt to revise 
these agreements due to the too large flow of Algerians. In the early 1970s, due to a reduction in labor requirements, France began to restrict immigration and managed to restrain migration flows until the beginning of the 20th and the modern wave of migration in Europe (Veretevskaya 2018). It is worth saying that in essence, France began to implement the policy of multiculturalism only at the end of the 20th century, despite the long experience of migration.

Currently, ethnic minorities are increasingly demanding in the question concerning the recognition of their cultural identity and their cultural practices, which are not "usual" for their receiving countries. An example is the requirement to recognise the customary law of ethnic minorities (Vasilyeva 1992; Abashidze 1996), or the demands of immigrants have their religious or cultural practices accepted, and in some cases to take them into account at the state level.

It can be said that the process of development and formation of new multicultural states is underway, but this is a complex and sometimes ambiguous process, which affects the interests of a large number of people and communities. In the foreground, there are the problems of the economic and social integration of cultural minorities, the tensions in the world facing terrorism issues, and, in addition, the increasing migration flows. Thus, the lives of migrants in their new countries of stay are causing a serious public response.

It is worth noting that nowadays a number of scientists claim that the multiculturalism policy only strengthens the cultural differences and does not weaken them. On the basis of such policy, cultural differences may be additionally emphasised and even exaggerated. The described policy has a negative impact both on the culture itself and on the possibilities of integration of the population within the society. In this case, the idea of multiculturalism is considered a source of destruction of social unity (Babich \& Rodionova 2009; Hasanova 2015; Tishkov 2002; Fukuyama 1995). In this context, an interesting point of view was expressed by F. Fukuyama, who, at the end of the last century, spoke about the inconsistency of multiculturalism, that it only cultivates disunity in the states (Hasanova 2015). According to Fukuyama, multiculturalism covers the reluctance of truly accepting other cultural values, and it integrates the lives of the minorities into the lives of the majority: "Let you have your own schools, your own religion, your community, and we will leave you alone if you leave us alone" (Fukuyama 1995: 310).

In the broadest sense, the multiculturalism policy is a range of ideas about the support and significance of ethnocultural diversity (Babich \& Rodionova 2009; Veretevskaya 2018; Tishkov 2002; Tully 2002; Raz 1994; Kucheryavaya \& Kucheriavaia 2016; Kucheriavaia 2018; Koroteeva 
1999; Van Dyke 1982; Blinova 2009; Volkova 2011). However, additional clarifying questions are appearing: on which particular groups of the population should be the policy of support focus, what exactly it should consist of, and who should deal with these striking theoretical and practical contradictions. Thus, despite the very widespread multiculturalism policy, it is impossible to speak about the formation of an unequivocal understanding of this phenomenon.

For example, according to the Canadian and New Zealand approaches, multiculturalism is understood as a policy of supporting ethnic diversity and ethnic minorities, by including and integrating them into a wider cultural group. A similar policy is being pursued with respect to the indigenous peoples and the immigrants. The measures themselves may differ depending on the state and the specific political situation in it. In Europe, multiculturalism appears to be a kind of specific and unpopular policy to support the cultural identity of the immigrants. An interesting point is that the inherent multiculturalism policy towards indigenous peoples or national minorities is not perceived by the European people as a manifestation of multiculturalism (Kymlicka 2007).

V.A. Tishkov (2002) proposed to utilise the concept of multiculturalism from the point of view of several aspects:

1) descriptively, when it comes to characterising a society with a large number of different ethnic, religious and cultural groups;

2) regulatory, when it is said about a certain group of political principles on which interaction with society is built;

3 ) in the political sphere, where multiculturalism is a series of political measures.

An important note on these aspects should be made based on the works of B. Parekh: it is necessary to distinguish a culturally diverse reality from a multicultural society itself (Parekh 2006). Multiculturalism should be discussed only when diversity is recognised in the society as a value and is supported both by political doctrine and by the society. Parekh introduces two terms in relation to society: "multicultural" and "multiculturalist". In the first case, it means the state, where there are several or more different cultural communities, and, in the second case, the similar societies demonstrate a positive attitude towards the introduction of diversity in value. However, the term "multicultural society" is not so ingrained in literature and is less commonly used to compare the effects. Thus, the mere presence in the state of a large number of isolated cultural groups does not make it a multicultural society, that society can rather be called "heterogeneous". 
A heterogeneous society, in which cultural diversity is regarded as a problem that needs to be overcome, will not be multicultural in the strict sense (Veretevskaya 2018; Parekh 2006).

Today, among the many different definitions of multiculturalism, there is no one that would allow us to judge, whether we are dealing in each case with multiculturalism, with a kind of multicultural approach, or with something resembling multiculturalism only by its shell. At the same time, as noted by W. Kymlicka (2007), with all the variety of understanding of the essence of the multiculturalism policy and the phenomenon as a whole, this is a very obvious phenomenon and can be recognised in various political conditions. Nevertheless, in spite of the solidarity with the above-mentioned opinion about the recognition of the phenomenon of multiculturalism, in order to make the notion of multiculturalism functional, it must be endowed with more specific internal content and made more capacious. It is also noteworthy that the goal of multiculturalism in the most general sense for the majority is seen in one thing - to ensure a non-conflict existence of a multicultural society in an economically prosperous and politically stable liberal state, based on the voluntary and full-fledged political integration of all cultural groups of society (Veretevskaya 2018). Only through the full inclusion of all cultural communities in the dialogue can be achieved the success in shaping a multicultural policy and its implementation. In our opinion, the key problem of multiculturalism in Europe lies in the absence of such a multicultural dialogue between all parties. Other reasons of the problems of developing a common multicultural policy in the European Union are the peculiarities of the decision-making process at the EU level (Lawniczak 2018).

In our opinion, Canada can be proud of having the most successful experience in implementing the multiculturalism policy. As mentioned above, Canada was the first country where the policy of integration was fixed at the legislative level. In addition, most of the Canadian population is ethnic Europeans, and, in terms of standard of living, Canada is comparable to the most developed European countries (Veretevskaya 2018; Lyalina 2014; McCoy 2018). Despite the fact that, obviously, Canada does not belong to the states of Europe, its political traditions go back to the European ones. The goal of implementing the multiculturalism policy in Canada is to ensure a comfortable and conflict-free existence of diverse cultures within one country, based on voluntary and full-fledged political integration. The achievement of this goal is primarily based on the acceptance and respect for a different culture by all parties of the dialogue (Bąk et al. 2019).

The principles underlying the multiculturalism policy in Canada are the following: 
1) the awareness of the importance (but not absolute) of the cultural component in the social and political life of the individuals and the society;

2) the equal inclusion of the representatives of all cultural groups of society in the public life of the society (e.g. ensuring access to participate in the definition of the common good);

3) the need for a partial voluntary cultural transformation in order to achieve a political consensus on the common good - a multicultural compromise;

4) the perception of a broad multi-format multicultural dialogue (polylogue) as the best way to achieve a legitimate multicultural compromise.

It is important to understand that all the goals and principles indicated above are fully observed, and this fact contributes to the successful implementation of the multiculturalism policy (Veretevskaya 2018).

The sharpest contradictions now arise due to the high increase of migrant flows from Muslim states. In most states, the society was not ready to accept them, in some cases even despite the fact of getting used to the arrival of migrant workers. It is important to understand that in this case the role is played not only by the unreadiness of society to seek a compromise and accept other cultural traditions and practices, but mainly by the unwillingness of the migrants themselves to adapt to life in a different culture. In this regard, there are natural contradictions, migrants cannot identify themselves with the state in which they are currently arriving and can join extremism in search of identity, which even James Cameron spoke about (Veretevskaya 2018). In such situation, we can understand the reluctance of some European states to take part in the multiculturalism policy and adapt to new reality, that is visible in political decisions and media discourse.

Despite the fact that at that time the countries of Central and Eastern Europe were invited to accept a smaller part of the refugees, who were being admitted by Germany and other countries, they put up fierce resistance. The Prime Minister of Slovakia, Robert Fico, said that his country would accept only Christian refugees, since the opposite would be "false solidarity" - to force Muslims to settle in a country without a single mosque. Viktor Orban, Prime Minister of Hungary, called the refugee flow a "riot of illegal migrants". The disagreements further divided the union, which then faced an unprecedented flow of migrants. Lech Walęsa, who led the Polish independence movement, said: "Our salaries and homes are still smaller than in the West. Many people here do not believe that they have something to share with migrants. Moreover, they see that migrants are often well dressed, sometimes better than some Poles" (Lyman 2015). 


\section{Conclusions}

The findings of our research demonstrate, that - unfortunately - nowadays there is a tendency to neglect the solution of the problems of multiculturalism. Instead of dealing with the mentioned issue by consistent implementation of the multiculturalism policy aiming at integration, ethnic, religious and cultural differences are even aggravated by the current policy makers. Immigration communities, and the migrants in general, do not have communication channels with the national and cultural majority; they cannot associate themselves with the state, where they are at the moment. Often, identity is not the product of a multicultural compromise accepted by the majority, but only a reflection of those values, which a large number of cultural communities do not have access to (Nikolaeva et al. 2018).

In conclusion, it should be said that the statement about the failure of the multiculturalism policy in Europe is controversial, due to the fact that in the end it cannot be said that such policy has ever been fully applied (Nechaev \& Volkova 2014; Kondratyeva 2011; Asa, Kivilehto \& Koljonen 2009; Csereklye 2014). Multiculturalism mostly remained only in political rhetoric, and the initiatives implemented in practice were chaotic and unsystematic. In addition, it is worth noting that the most successful multiculturalism policies in the selected European countries were aimed at non-immigrant minorities, while immigrant policies are more suited to either segregation or assimilation. All the efforts of European "multiculturalism" were aimed at making immigrants look like the people in the states they came; however, this is not integration, and certainly not multiculturalism. The real multiculturalism policy is based on the respect for different cultures and worldviews, but absolutely all aspects of multicultural dialogue should certainly come to this respect: multiculturalism did not fail in Europe, they simply did not try to instill it truly (Bakır 2018). However, the events of the last decade demonstrate, that the popularity of the idea of multiculturalism is declining with the growing number of those Europeans who want to return to the "traditional Europe" with borders closed to migrants and with the traditional division in accordance with ethno-cultural criteria. This means an existential danger to these states, and, unfortunately, in this case there can be no prospects for the development of multiculturalism. Instead, radical ideas and radical politicians have great prospects.

During the last years the concept of multiculturalism has anchored itself in the speech of politicians and media in many European countries. Multiculturalism has become an ideology (not only a policy), that has on one hand gained a lot of support from some parties and, on the other 
hand, received a lot of criticism. In the academic discussion different views have been expressed: how multiculturalism can enrich culture and life or, as opposite, how multiculturalism can threaten the coherency of the nation (Asa, Kivilehto \& Koljonen 2009).

On the basis of the presented partial analysis it is difficult to make wide-spead and going to the distant future prognosis. However, when drawing conclusions, it should be assumed that, unlike the examples analysed at the national level, the prospect of success of the pan-European programme will also be determined by transnational trends and glocalisation processes - as a feedback wave effect on globalisation processes (Witkowska 2013). These trends mean that today it is impossible to create the reasonable assumptions for the projection of the future of multiculturalism policy at the European level. At the same time, we understand that the raised issue of multiculturalism policy is extremely important nowadays and it deserves in-depth research and a wide scientific discussion. However, taking into consideration formal requirements for this particular publication and the aim of the article, we are not able to present wider aspects of the topic and the in-depth analysis of all related issue. Although, paying careful attention to the importance of the problem we will continue research on the topic and present the outcomes of our work in the future publications.

The Canadian experience analysed in this article can be useful for the European states in improving and implementing the current multiculturalism policy. The process of solving the problems of multiculturalism is very long and laborious; an important role in it is played by the desire of minorities themselves to integrate and become part of a larger culture, while maintaining their own traditions. Thus, the success of the multiculturalism policy lies in the systematic, consistent and continuous multicultural dialogue aimed at reaching a compromise and finding effective solutions.

\section{Acknowledgements}

This publication has been prepared with the support of the "RUDN University Program 5-100". The co-authors are members of international research group in the field of multiculturalism policy.

\section{References}

1. Abashidze, A.Kh., (1996) Protection of minority rights under international and domestic law, Moscow: Human Rights. 
2. Asa, R., Kivilehto, M., Koljonen, T. (2009), Annual Policy Report, Helsinki, Finland.

3. Babich, I.L., Rodionova, O.V. (2009) Theory and practice of multiculturalism. In: Research on applied and urgent ethnology. Moscow: IEA RAS. Vol. 215.

4. Bakır, Z. (2018) The Fall of Multiculturalism in Europe and Muslims. In: iNSAMER, 2018 .

5. Bąk, T., Kardis, M., Valco, M., Kalimullin, A., Galushkin, A. (2019) A philosophicalsociological diagnosis of youth subcultures in the context of social changes. In: XLinguae. 2(12), 163-185.

6. Blinova, M.S. (2009) Modern sociological theories of population migration. Moscow.

7. Csereklye, E. (2014) Multiculturalism in Central and Eastern Europe: The Hungarian story. In: Multicultural Education Review. Volume 6, Issue 1

8. Cuyjet, M.J., Linder, Ch., Howard-Hamilton, M.F., Cooper, D.L. (2016) Multiculturalism on Campus: Theory, Models, and Practices for Understanding Diversity and Creating Inclusion, Second edition. Sterling, Virginia: Stylus Publishing.

9. Fukuyama, F. (1995) The end of the story? In: Philosophy of history. Anthology. Moscow.

10. Hasanova, N. K. (2015) On the definition of the concept “multiculturalism”. In: Cultural life of the south of Russia. 1, 10-16.

11. Kondratyeva, T.S. (2011) United Kingdom: The failure of multiculturalism. In: Actual problems of Europe. 4, 35-78.

12. Koroteeva, V.V. (1999) Theories of nationalism in the foreign social sciences. Moscow: Publishing House of the RSUH.

13. Kucheriavaia, S. (2018) Main approaches to the problem of overcoming stereotypes in the contemporary society. In: Chelovek. Gosudarstvo. Pravo. No. 1/2018 [Человек. Государство. Право]

14. Kucheryavaya, E., Kucheriavaia, S. (2016) Stereotypes in Polish-German Economic Cooperation. In: Studia Politica Germanica. 1(5), 29-44.

15. Kymlicka, W. (2007) Multicultural Odysseys. Navigating the New International Politics of Diversity. New York: Oxford University Press.

16. Lawniczak, K. (2018) Socialisation and legitimacy intermediation in the Council of the European Union. In: Perspectives on Federalism. 10(1), 202-221 
17. Lyalina, A.V. (2014) Experience of the national policy of integration of EU migrants. In: Baltic region. No. 2.

18. Lyman, R. (2015) Eastern Bloc's Resistance to Refugees Highlights Europe's Cultural and Political Divisions. In: The New York Times, https://www.nytimes.com/2015/09/13/world/europe/eastern-europe-migrant-refugeecrisis.html (13.09.2015)

19. Meer, N. (2016), Multiculturalism and Interculturalism: Debating the Dividing Lines. Edinburgh: Edinburgh University Press.

20. McCoy, J.S. (2018) Protecting Multiculturalism : Muslims, Security, and Integration in Canada. Montreal: MQUP.

21. Nechaev, D.N., Volkova, A.E. (2014) Models and practices of resolving ethnic and cultural contradictions in national states: international experience. In: Srednerussky Bulletin of Social Sciences. No. 2.

22. Nikolaeva, Y.V., Grimalskaya, S.A., Petrosyants, D.V., Zulfugarzade, T.E., Maystrovich, E.V., Shestak, V.A. (2018) Philosophical view of multiculturalism in modern European cinematography. In: European Journal of Science and Theology. 14(6), 205-214. [doi: 10.5281/zenodo.1472151]

23. Parekh, B. (1999) What is muilticulturalism? In: Multiculturalism. A symposium on democracy in culturally diverse societies. No. 484

24. Parekh, B. (2006) Rethinking Multiculturalism: Cultural Diversity and Political Theory. New York: Palgrave Macmillan.

25. Petrakov, Ia., Kucheryavaya, E. (2016) Between failure and success of the integration process: explaining the policy impact (the case of the fiscal and energy unions). In: Przegląd Europejski. 4 (42).

26. Raz, J. (1994) Multiculturalism: A Liberal Perspective. In: Dissent. 4, 67-79.

27. Sitnikova E. L. (2009) Ideas of the Chicago School of Sociology in modern studies of population migration. In: Bulletin of the Nizhny Novgorod University. N.I. Lobachevsky. Series: Social Sciences. 4, 118-123

28. Terborn G. (2001) Mul'tikul'turnye obshchestva. In: Sotsiologicheskoe obozrenie. T. 1, № $1,50-67$. 
29. Tishkov, V.A. (2002) Theory and practice of multiculturalism. In: Malakhov, V.S., Tishkov V.A., Multiculturalism and transformation of post-Soviet societies. Moscow.

30. Tully, J. (2002) The illiberal liberal: Brian Barry's Polemical Attack on Multiculturalism. In: Kelly, P. (ed.), Multiculturalism Reconsidered: Culture and Equality and Its Critics. Cambridge: Polity Press.

31. Triandafyllidou, A., Modood, T., Meer, N. (2012) European Multiculturalisms: Cultural, Religious and Ethnic Challenges, Edinburgh: Edinburgh University Press.

32. Van Dyke, V. (1982) Collective Rights and Moral Rights: Problems in LiberalDemocratic Thought. In: Journal of Politics. 44, 21-40.

33. Vasilyeva, T.A. (1992) The legal status of ethnic minorities in Western Europe. In: State and law. 8, 133-142.

34. Veretevskaya, A.V. (2018) Multiculturalism, which was not: an analysis of European practices of political integration of ethnic and cultural minorities. Moscow: MGIMOUniversity.

35. Volkova, T.P. (2011) Classical philosophical concepts of multiculturalism and tolerance. In: Vestnik MGTU. No. 2.

36. Witkowska, M. (2013), Transnational approach in research over political processes in the European Union, In: Studia Politologiczne. 27, 122-137. 